\title{
Does lethal control of top-predators release mesopredators? A re-evaluation of three Australian case studies
}

\author{
By Benjamin L. Allen, Geoff Lundie-Jenkins, Neil D. Burrows, Richard M. Engeman, \\ Peter J.S. Fleming and Luke K.-P. Leung
}

Benjamin L. Allen is a wildlife ecologist with the University of Queensland (current address: Robert Wicks Pest Animal Research Centre, Biosecurity Queensland, Toowoomba, Qld 4350, Australia; Email: benjamin.allen@daff.qld. gov.au; Tel: 6174688 1294). Geoff LundieJenkins is senior manager with the Department of Environment and Heritage Protection (Toowoomba, Qld 4350, Australia; Email: geoff.lundie-jenkins@ehp.qld.gov.au). Neil D. Burrows is a senior principal research scientist with the Department of Parks and Wildlife (Kensington, WA 6153, Australia; Email: neil.burrows@dpaw. wa.gov.au). Richard M. Engeman is an ecologist and biometrician with the United States Department of Agriculture (National Wildlife Research Centre, Fort Collins, CO 8051-2154, USA; Email: richard.m.engeman@aphis.usda. gov). Peter J.S. Fleming is a wildlife ecologist and principal research scientist with the Department of Primary Industries (Vertebrate Pest Research Unit, Orange, NSW 2800, Australia; Email: peter.fleming@dpi.nsw.gov.au). Luke K.-P. Leung is a senior ecologist with the University of Queensland (School of Agriculture and Food Sciences, the University of Queensland, Gatton, Qld 4343, Australia; Email: luke.leung@ uq.edu.au).

\begin{abstract}
Summary Top-predators can sometimes be important for structuring fauna assemblages in terrestrial ecosystems. Through a complex trophic cascade, the lethal control of top-predators has been predicted to elicit positive population responses from mesopredators that may in turn increase predation pressure on prey species of concern. In support of this hypothesis, many relevant research papers, opinion pieces and literature reviews identify three particular case studies as supporting evidence for top-predator controlinduced release of mesopredators in Australia. However, many fundamental details essential for supporting this hypothesis are missing from these case studies, which were each designed to investigate alternative aims. Here, we re-evaluate the strength of evidence for top-predator control-induced mesopredator release from these three studies after comprehensive analyses of associated unpublished correlative and experimental data. Circumstantial evidence alluded to mesopredator releases of either the European Red Fox (Vulpes vulpes) or feral Cat (Felis catus) coinciding with Dingo (Canis lupus dingo) control in each case. Importantly, however, substantial limitations in predator population sampling techniques and/or experimental designs preclude strong assertions about the effect of lethal control on mesopredator populations from these studies. In all cases, multiple confounding factors and plausible alternative explanations for observed changes in predator populations exist. In accord with several critical reviews and a growing body of demonstrated experimental evidence on the subject, we conclude that there is an absence of reliable evidence for top-predator control-induced mesopredator release from these three case studies.

Well-designed and executed studies are critical for investigating potential top-predator control-induced mesopredator release.
\end{abstract}

Key words: lethal control, mesopredator release, poison baiting, top-predator, trophic cascade.

\section{Introduction}

The outcomes of top-predator interactions with other fauna can have important ramifications for structuring food webs and faunal assemblages in terrestrial ecosystems. This is because the roles of top-predators can include suppression of sympatric mesopredators and prey, which may ultimately provide net benefits to fauna and flora at lower trophic levels (Estes et al. 2011; Ripple et al. 2014). Through a complex trophic cascade, the lethal control of top-predators might therefore elicit positive responses from mesopredator populations (that is, mesopredator release), which could in turn increase predation pressure on prey threatened by mesopredators (Crooks \& Soulé 1999). Understanding the actual ecological outcomes of predator control is fundamental to the development of bestpractice wildlife management strategies in many places (Allen et al. 2014b).

Predation by the introduced European Red Fox (Vulpes vulpes; 4-8 kg) and feral
Cat (Felis catus; $4-6 \mathrm{~kg}$ ) (hereafter referred to as fox and cat) are key threatening processes, inhibiting the recovery and conservation of many threatened fauna in Australia. These two species are mesopredators relative to the larger Dingo (Canis lupus dingo and other free-roaming Canis; $12-17 \mathrm{~kg}$; hereafter referred to as dingo). Lethal dingo control, such as opportunistic shooting, trapping and/ or poison baiting is commonly practiced to mitigate their well-documented impacts on livestock and some threatened fauna 
(e.g. Allen \& Fleming 2012; Fleming et al. 2012b). These lethal control practices have recently received increased scrutiny for their perceived indirect benefits to fox and cat populations, culminating in calls to prohibit lethal dingo control with the expectation that dingoes will then reduce the abundance of foxes and cats and their impacts on threatened prey (e.g. Johnson 2006; Dickman et al. 2009; Carwardine et al. 2011; Brook et al. 2012; Ritchie 2014).

In the last 10 years, there have been at least 22 literature reviews and extended opinion pieces specifically discussing available data on this subject (Table A1, Appendix S1). Within these, the merits of three particular case studies are often mooted as evidence for dingo controlinduced mesopredator release of foxes or cats (DC-IMR). The workshop narrative of Pettigrew (1993) reports a 'burst of feral Cats' following the shooting of $\sim 50$ dingoes around an isolated Greater Bilby (Macrotis lagotis) population in arid south-west Queensland; the journal article of Lundie-Jenkins et al. (1993) documents the demise of one small Rufous Harewallaby or Mala (Lagorchestes birsutus) population in the Tanami Desert of central northern Australia shortly after a smallscale dingo baiting programme was undertaken; and the book chapter of Christensen and Burrows (1995) discusses the reintroduction success of two medium-sized mammals to the Gibson Desert of Western Australia, relative to associated dingo, fox and cat control activities. Eleven of the 22 works involving dingoes and mesopredators cited one or more of these case studies as providing evidence for DC-IMR (Table A1). Only three of these specifically discussed the stated caveats or methodological limitations of these three case studies (Table A1), although some others describe the case studies in terms of the 'anecdotal' or 'circumstantial' evidence they provide (e.g. Glen \& Woodman 2013).

Several critical reviews of methods and a growing number of manipulative experiments have demonstrated both an absence of evidence and evidence of absence for DC-IMR (e.g. Eldridge et al. 2002; Allen et al. 2013a,b). In recent debate, however, the three aforementioned cases are commonly identified as studies that suggest exceptions to this rule (e.g. Glen 2012; Johnson \& Ritchie 2013). Although absolute claims about the strength of the evidence base for DC-IMR are usually tempered, many studies implicitly or explicitly advocate changes to current dingo management practices on the data available, such as cessation of dingo control or active reintroduction of dingoes to the few remaining places they are absent (e.g. Dickman et al. 2009; Wallach et al. 2010; Letnic et al. 2013). Others contend that the information requisite for reliably assessing DC-IMR is not available in these three case studies or most others (Allen et al. 2012; Claridge 2013; Fleming et al. 2013) and, in line with the precautionary principle, dingo management changes should not occur until the evidence warrants it (Allen \& Fleming 2012; Fleming et al. 2012a). Unfortunately, limited effort has been devoted to clearly demonstrating whether or not these three case studies can be used as reliable evidence for DC-IMR.

To exhaustively search for potential evidence of DC-IMR from these three studies, we re-evaluated them in light of additional unpublished data not included in the original reports. Our aim was to demonstrate whether or not reliable evidence for DC-IMR can be obtained from these three studies. Comprehensive details on the background, methods and results of our evaluations are provided in the Appendices (Appendices S1-S4 online), as are explicit descriptions of the differences in available data between the original reports and our analyses. The following information is best understood after familiarization with the content of these Appendices.

\section{Case Study 1 - Pettigrew (1993)}

An increase in cat activity at the site where dingoes were shot led Pettigrew (1993) to conclude, and others to repeat (e.g. Glen \& Dickman 2005; Ritchie \& Johnson 2009), that shooting dingoes was responsible for observed cat increases. However, the available data are unsuitable to con- firm causal factors for observed changes in cat abundance indices primarily because of the lack of precision inherent in the predator population sampling technique used (Appendix S2).

The experimental design was excellent, including treatment and replicated nil-treatment areas monitored over time both before and after lethal dingo control (Fig. B1, B2). However, opportunistic daytime counts of dingoes and cats sighted were poor measures of their activity and relative abundance; the median number of cats and dingoes sighted per survey was only one and two animals, respectively (Table B1). Furthermore, more than 800 cats were shot while roosting in trees during the day over a three-month period in the treatment area alone, while daytime surveys detected a total of only 229 cats from all treatments over the entire 27-month study, and of these, 137 were detected during just one of the 10 surveys (Table B1). The predator sampling technique clearly struggled to detect predators that were obviously present.

Primary and higher-inference analyses yielded some indication that cat abundance indices increased faster in the area where dingoes were shot than in the two areas dingoes were not shot. However, conflicting information exists about the exact numbers of dingoes shot (Appendix S2), and shooting did not produce detectable changes in dingo abundance indices (Tables B2, B3 and B5). A variety of supplementary and lower-inference analyses failed to add trustworthy evidence of inverse relationships between dingo and cat abundance indices (Appendix S2).

These results may be due to the true absence of any significant dingo-cat interactions. Alternatively or additionally, the predator indexing technique used may not have reflected the true abundance of extant cats and dingoes or had sufficient precision to detect changes in their abundances. If any of these explanations hold, then assertions about the impacts of dingo control on mesopredator abundance are precluded.

Another possible interpretation of these results is that dingo populations subject to shooting were functionally differ- 
ent to those that were not. In other words, although dingo abundance did not change markedly, surviving dingoes may have behaved differently towards cats to the point that cats were no longer suppressed by dingoes. If this were the case, and dingoes were truly suppressing or limiting cats in the area, negative correlations between dingoes and cats under normal conditions might be expected (Kennedy et al. 2012), but such was not apparent (Appendix S2). That bilby (i.e. mediumsized prey) densities were five times greater in the treated area (22 Greater Bilby burrows $/ \mathrm{km}^{2}$ ) than in the other two nil-treatment areas (four Greater Bilby burrows $/ \mathrm{km}^{2}$ ) (McRae 2004) may help explain why greater increases of cats were observed in the treated area. That almost all cats shot in the few months after the dingoes were shot were adult cats in prime physical condition (Table $\mathrm{B} 4$ and Pettigrew 1993) further suggests a largescale immigration of nonresident cats, too rapid to be explained by increased breeding success of extant cats. One might also question where these immigrating cats came from if dingoes outside the treated area were suppressing or limiting cats there.

At the time, the phenomenal burst of cats observed in 1992 was considered so unusual as to be one that was unlikely to again be witnessed for some time (Pettigrew 1993). However, similar events subsequently occurred in 1996 and between 2010 and 2013, when similarly large bursts of cats were again observed shortly after rainfall-induced increases in prey availability (McRae 2004; P. McRae, unpublished data). Of relevance to the present study, lethal dingo control had not occurred before either event at the study site. Thus, our results suggest that cat population trends at the site were independent of dingoes or the limited lethal dingo control that occurred.

\section{Case Study 2 - Lundie- Jenkins et al. (1993)}

The detection of foxes (and the subsequent extinction of mala) shortly after the first dingo control event at the site has been interpreted by some as evidence for DC-IMR (e.g. Letnic et al. 2012). However, as a 'simple observation' (sensu Hone 2007), the data of LundieJenkins et al. (1993) do not provide reliable information on the responses of foxes or cats to dingo control, nor do the available data provide evidence for dingo control-induced extinction of mala (Appendix S3). With respect to investigating DC-IMR, the experimental design and small scale of the study was insufficient for inferring population-level changes in predators (Fig. C1). While dingoes were not detected on quadrats during the September 1987 survey, coincident with baiting (Fig. C2), dingo activity is known to naturally decline between July and November during dingoes' annual whelping season independent of lethal control (e.g. Allen et al. 2011a). Moreover, the presence of fox tracks and evidence of fox predation was observed at the same time as dingo activity recovered, not when dingoes were undetected (Lundie-Jenkins et al. 1993; Lundie-Jenkins 1998).

To suggest that lethal dingo control caused a release of foxes or cats from a single opportunistic observation is to extend inferences far beyond the limitations of the data (Hone 2007; Fleming et al. 2013). To infer from the data in this study that dingo control caused the local extinction of mala does not recognize the persistence of the second, nearby colony of mala that did not go extinct in response to baiting, but was instead destroyed by wildfire (Gibson et al. 1995). Equally, it does not adequately reconcile with contemporary views regarding the key drivers of mala decline in the first place (views based on subsequent research; e.g. Allen et al. 2012; Lundie-Jenkins 1998).

\section{Case Study 3 - Christensen and Burrows (1995)}

An increase in cat activity following the poison baiting of dingoes and foxes has led some to conclude that canid control was responsible for the increase in cats. However, the experimental design used in the study of Christensen and Burrows (1995) also precludes reliable inferences about DC-IMR (Appendix S4). Cat population indices were indeed much greater in the latter stages of the study coincident with lower dingo and fox indices (Fig. D2). However, and as recognized in the original studies, changes in cat indices were coincident with multiple simultaneous perturbations: cessation of cyanide baiting (which targeted cats and foxes, as well as dingoes), commencement of 1080 baiting (with increasing bait densities), substantial rainfall events and also a change in the physical location of the unbaited niltreatment area. Any of these could have each caused or contributed to the observed changes in predator indices. The imprecision of the predator population sampling techniques is also implicated here again, with follow-up trials specifically investigating the responses of cats to canid control at the site likewise providing 'inconclusive' data due to the limitations of the sampling methodology (Burrows et al. 2003, pg. 708).

Given the limitations to the design and execution of the study, it is impossible to confidently evaluate the relative contributions of rainfall, predator control or treatment relocation to the observed changes in predator indices over the study period. What may be reliably gleaned from this case study is that the distribution of poisoned baits can sometimes control foxes and dingoes, but that this alone may be insufficient to facilitate the establishment of reintroduced mammals (Christensen \& Burrows 1995); hence, the shift in research focus towards controlling cats (e.g. Algar \& Burrows 2004; Christensen et al. 2013).

\section{Conclusions}

We conclude that these three case studies provide no reliable evidence for DC-IMR (Appendices S2-S4). This is primarily because (i) there is little reliable evidence that dingo populations were actually affected by control to any substantial degree (i.e. the prerequisite to a controlinduced trophic cascade was not demonstrated), (ii) limitations to experimental designs and/or predator sampling methods meant that the three studies were each incapable of reliably evaluating predator responses to dingo control and (iii) 
because DC-IMR remains only one of several plausible alternative explanations for the observations.

Other studies using predator sampling methodologies and experimental designs with greater inferential capacity to separate the effects of multiple explanatory variables have consistently demonstrated mesopredator population fluctuations to be independent of dingoes or dingo control at a dozen sites across the tropical, semi-arid and arid rangelands of northern, central and southern Australia (Allen et al. 2013a; Eldridge et al. 2002; but see also comment by Johnson et al. 2014 and response by Allen et al. 2014a). Long-term (i.e. 10-28 years) correlations between dingo, fox and cat population indices likewise reveal the supremacy of bottom-up factors for influencing predator population dynamics in temperate south-eastern Australia (Claridge et al. 2010; Arthur et al. 2013).

Almost all available studies reporting dissimilar results are based on demonstrably confounded predator population sampling methods and/or low-inferential value study designs that simply do not have the capacity to provide reliable evidence for DC-IMR (e.g. Allen et al. 2011a,b, 2013b; Allen 2012; Claridge 2013). Some have downplayed the importance of the systemic predator population sampling flaws present throughout the literature (i.e. Letnic et al. 2011; Glen 2012), and others have questioned the theoretical background for believing that dingoes might not provide net benefits to biodiversity (i.e. Johnson \& Ritchie 2013), but the inability of snapshot, observational or correlative study designs for providing conclusive evidence of DC-IMR is indisputable, no matter how many such studies might accumulate. Thus, dingo control-induced releases of foxes or cats have not yet been demonstrated in any available study. The data in Pettigrew (1993), Lundie-Jenkins et al. (1993) and Christensen and Burrows (1995) do not contradict this view (Appendices S2-S4), and no amount of reviewing and rereviewing the presently available literature can show otherwise (Appendix S1).

Although there are some broad patterns among top-predators, mesopredators and their prey in some contexts (Estes et al. 2011; Ripple et al. 2014) and there are good reasons to suspect these processes also occur for dingoes (because they occur between foxes and cats; Risbey et al. 2000), we are still far from a point where the patterns and processes between dingoes, foxes and cats suggestive of DC-IMR can be separated from equally plausible alternative interpretations (e.g. Allen 2011; Fleming et al. 2012a; Claridge 2013). 'Hence, it is premature to call for widespread cessation of dingo control on biodiversity protection grounds' (Glen 2012, pg. 857), and the three case studies we have re-evaluated here should not be misconstrued as providing support for the belief that ceasing lethal dingo control will do so. We do not contend that dingoes do not present cascading benefits to biodiversity in some circumstances or that dingo control does not harm biodiversity in others. Rather, we advocate evidence-based wildlife management approaches that do not unduly risk valuable environmental and economic assets, such as threatened fauna and livestock industries. We hope that our study adds some clarity to the evidence base for top-predator controlinduced mesopredator release and we continue to encourage further work on this important subject.

\section{Acknowledgements}

We sincerely thank all those who contributed to the production of the three original case studies. We especially acknowledge Emeritus Professor Jack Pettigrew for providing unpublished data, details about his original research, many helpful comments and much direction on several earlier drafts. We also thank Dave Algar, Guy Ballard, James Speed, Per Christensen, Rachael Paltridge, Steve Eldridge and Tom Newsome for contributing unpublished data and/or helpful insights into the history and characteristics of the study sites. Joe Scanlan, Lee Allen and Matt Gentle provided useful comments on earlier drafts of the manuscript. For the case study of Pettigrew (1993), supplementary analyses were published at the request of the reviewers. The conclusions we have drawn from the analyses are our own and should not be construed to reflect the views of anyone other than the authors of this paper. This work was completed as part of research supported by the Invasive Animals Cooperative Research Centre.

\section{References}

Algar D. and Burrows N. D. (2004) Feral cat control research: Western Shield review February 2003. Conservation Science Western Australia 5, 131-163.

Allen B. L. (2011) A comment on the distribution of historical and contemporary livestock grazing across Australia: implications for using dingoes for biodiversity conservation. Ecological Management \& Restoration 12, 26-30.

Allen B. L. (2012) Scat happens: spatiotemporal fluctuation in dingo scat collection rates. Australian Journal of Zoology 60, 137-140.

Allen B. L. and Fleming P. J. S. (2012) Reintroducing the dingo: the risk of dingo predation to threatened vertebrates of western New South Wales. Wildlife Research 39, 35-50.

Allen B. L., Engeman R. M. and Allen L. R. (2011a) Wild dogma I: an examination of recent "evidence" for dingo regulation of invasive mesopredator release in Australia. Current Zoology 57, 568-583.

Allen B. L., Engeman R. M. and Allen L. R. (2011b) Wild dogma II: the role and implications of wild dogma for wild dog management in Australia. Current Zoology 57, 737-740.

Allen B. L., Fleming P. J. S., Hayward M. et al. (2012) Top-predators as biodiversity regulators: contemporary issues affecting knowledge and management of dingoes in Australia. In: Biodiversity Enrichment in a Diverse World (ed. G. A. Lameed) pp. 85132. InTech Publishing, Rijeka, Croatia.

Allen B. L., Allen L. R., Engeman R. M. and Leung L. K.-P. (2013a) Intraguild relationships between sympatric predators exposed to lethal control: predator manipulation experiments. Frontiers in Zoology 10, 39.

Allen B. L., Fleming P. J. S., Allen L. R., Engeman R. M., Ballard G. and Leung L. K.-P. (2013b) As clear as mud: a critical review of evidence for the ecological roles of Australian dingoes. Biological Conservation 159, 158-174.

Allen B. L., Allen L. R., Engeman R. M. and Leung L. K.-P. (2014a) Reply to the criticism by Johnson et al. (2014) on the report by Allen et al. (2013). Frontiers in Zoology. [Accessed 1 June 2014.] Available from URL: http:// www.frontiersinzoology.com/content/11/11/ 17/comments\#1982699.

Allen B. L., Engeman R. M. and Leung L. K.-P. (2014b) The short-term effects of a routine poisoning campaign on the movement behaviour and detectability of a social top-predator. Environmental Science and Pollution Research 21, 2178-2190.

Arthur A. D., Catling P. C. and Reid A. (2013) Relative influence of habitat structure, species interactions and rainfall on the post-fire population dynamics of ground-dwelling vertebrates. Austral Ecology 37, 958-970. 
Brook L. A., Johnson C. N. and Ritchie E. G. (2012) Effects of predator control on behaviour of an apex predator and indirect consequences for mesopredator suppression. Journal of Applied Ecology 49, 1278-1286.

Burrows N. D., Algar D., Robinson A. D., Sinagra J., Ward B. and Liddelow G. (2003) Controlling introduced predators in the Gibson Desert of Western Australia. Journal of Arid Environments 55, 691-713.

Carwardine J., O'Connor T., Legge S., Mackey B., Possingham H. P. and Martin T. G. (2011) Priority threat Management to Protect Kimberley Wildlife. CSIRO Ecosystem Sciences, Brisbane.

Christensen P. and Burrows N. (1995) Project Desert Dreaming: experimental reintroduction of mammals to the Gibson Desert, Western Australia. In: Reintroduction Biology of Australian and New Zealand Fauna (ed. M. Serena) pp. 199-207. Surrey Beatty \& Sons, Chipping Norton

Christensen P. E. S., Ward B. G. and Sims C. (2013) Predicting bait uptake by feral cats, Felis catus, in semi-arid environments. Ecological Management \& Restoration 14, 47-53.

Claridge A. W. (2013) Examining interactions between dingoes (wild dogs) and mesopredators: the need for caution when interpreting summary data from previously published work. Australian Mammalogy 35, 248-250.

Claridge A. W., Cunningham R. B., Catling P. C. and Reid A. M. (2010) Trends in the activity levels of forest-dwelling vertebrate fauna against a background of intensive baiting for foxes. Forest Ecology and Management 260, 822-832

Crooks K. R. and Soulé M. E. (1999) Mesopredator release and avifaunal extinctions in a fragmented system. Nature 400, 563-566.

Dickman C., Glen A. and Letnic M. (2009) Reintroducing the dingo: can Australia's conservation wastelands be restored? In: Reintroduction of Top-Order Predators (eds M. W. Hayward and M. J. Somers) pp. 238 269. Wiley-Blackwell, Oxford.

Eldridge S. R., Shakeshaft B. J. and Nano T. J. (2002) The Impact of Wild Dog Control on Cattle, Native and Introduced Herbivores and Introduced Predators in Central Australia. Final report to the Bureau of Rural Sciences, Parks and Wildlife Commission of the Northern Territory, Alice Springs.

Estes J. A., Terborgh J., Brashares J. S. et al. (2011) Trophic downgrading of planet earth. Science 333, 301-306.

Fleming P. J. S., Allen B. L. and Ballard G. (2012a) Seven considerations about dingoes as biodiversity engineers: the socioecological niches of dogs in Australia. Australian Mammalogy 34, 119-131.

Fleming P. J. S., Allen B. L., Ballard G. and Allen L. R. (2012b) Wild Dog Ecology, Impacts and Management in Northern Australian Cat- tle Enterprises: a Review with Recommendations for $R$, D\&E investments. Meat and Livestock Australia, Sydney.

Fleming P. J. S., Allen B. L. and Ballard G. (2013) Cautionary considerations for positive dingo management: a response to the Johnson and Ritchie critique of Fleming et al. (2012). Australian Mammalogy 35, 15-22.

Gibson D. F., Johnson K. A. L., Langford D.G. Cole J. R., Clarke D. E. and Willowra community (1995) The rufous hare-wallaby Lagorchestes hirsutus: a history of experimenta reintroduction in the Tanami Desert, Northern Territory. In: Reintroduction Biology of Australian and New Zealand Fauna. (ed. M. Serena) pp. 171-176. Surrey Beatty \& Sons, Chipping Norton.

Glen A. S. (2012) Enough dogma: seeking the middle ground on the role of dingoes. Current Zoology 58, 856-858.

Glen A. S. and Dickman C. R. (2005) Complex interactions among mammalian carnivores in Australia, and their implications for wildlife management. Biological Reviews 80, 387 401.

Glen A. S. and Woodman A. P. (2013) What Impact does Altering Dingo Populations have on Trophic Structure?. Environmental Evidence Australia, Newcastle.

Hone J. (2007) Wildlife Damage Control. CSIRO Publishing, Collingwood, Victoria.

Johnson C. (2006) Australia's Mammal Extinctions: A 50000 year History. Cambridge University Press, Melbourne.

Johnson C. N. and Ritchie E. (2013) The dingo and biodiversity conservation: response to Fleming et al. (2012). Australian Mammalogy 35, 8-14.

Johnson C. N., Crowther M. S., Dickman C. R. et al. (2014) Experiments in no-impact control of dingoes: comment on Allen et al. 2013. Frontiers in Zoology 11, 17.

Kennedy M., Phillips B., Legge S., Murphy S. and Faulkner R. (2012) Do dingoes suppress the activity of feral cats in northern Australia? Austral Ecology 37, 134-139.

Letnic M., Crowther M. S., Dickman C. R. and Ritchie E. G. (2011) Demonising the dingo: how much wild dogma is enough? Current Zoology 57, 668-670.

Letnic M., Ritchie E. G. and Dickman C. R. (2012) Top predators as biodiversity regulators: the dingo Canis lupus dingo as a case study. Biological Reviews 87, 390-413.

Letnic M., Baker L. and Nesbitt B. (2013) Ecologically functional landscapes and the role of dingoes as trophic regulators in south-eastern Australia and other habitats. Ecological Management \& Restoration 14, 101-105.

Lundie-Jenkins G. W. (1998) Reintroduction of the mala to Aboriginal land in the Tanami Desert. Northern Territory: a case study of the reintroduction process as a research and management tool, $\mathrm{PhD}$ thesis, The Uni- versity of New England, Armidale, New South Wales.

Lundie-Jenkins G., Corbett L. K. and Phillips C. M. (1993) Ecology of the rufous hare-wallaby, Lagorchestes hirsutus Gould (Marsupialia: Macropodidae), in the Tanami Desert, Northern Territory. III. Interactions with introduced mammal species. Wildlife Research 20 , 495-511.

McRae P. D. (2004) Aspects of the ecology of the greater bilby, Macrotis lagotis Queensland thesis. University of Sydney, Sydney.

Pettigrew J. D. (1993) A burst of feral cats in the Diamantina: a lesson for the management of pest species? In: Cat Management Workshop Proceedings (eds G. Siepen and C. Owens) pp. 25-32. Brisbane, Queensland, Department of Environment and Heritage.

Ripple W. J., Estes J. A., Beschta R. L. et al. (2014) Status and ecological effects of the world's largest carnivores. Science $\mathbf{3 4 3}$, 151-163.

Risbey D. A., Calver M. C., Short J., Bradley J. S. and Wright I. W. (2000) The impact of cats and foxes on the small vertebrate fauna of Heirisson Prong, Western Australia. II. A field experiment. Wildlife Research 27, 223-235.

Ritchie E. G. (2014) The world's top predators are in decline, and it's hurting us too. The Conversation 10th January 2014. [Accessed 11 January 2014.] Available from URL: http://theconver sation.com/the-worlds-top-predators-are-indecline-and-its-hurting-us-too-21830.

Ritchie E. G. and Johnson C. N. (2009) Predator interactions, mesopredator release and biodiversity conservation. Ecology Letters 12 982-998.

Wallach A. D., Johnson C. N., Ritchie E. G. and O'Neill A. J. (2010) Predator control promotes invasive dominated ecological states. Ecology Letters 13, 1008-1018.

\section{Supporting Information}

Additional Supporting Information may be found in the online version of this article: Appendix 51. Literature reviews and extended opinion pieces discussing dingo control-induced mesopredator release.

Appendix S2. Re-evaluation of the published and unpublished data of Pettigrew (1993).

Appendix S3. Re-evaluation of the published and unpublished data of LundieJenkins et al. (1993).

Appendix S4. Re-evaluation of the published and unpublished data of Christensen and Burrows (1995). 